\title{
Weight Loss Expectations in Obese Patients and Treatment Attrition: An Observational Multicenter Study
}

\author{
Riccardo Dalle Grave, * Simona Calugi, * Enrico Molinari, †* Maria Letizia Petroni, $\$$ Mario Bondi, Il \\ Angelo Compare, $\$$ \$ Giulio Marchesini, $\|$ and the QUOVADIS Study Group**
}

\begin{abstract}
DALLE GRAVE, RICCARDO, SIMONA CALUGI, ENRICO MOLINARI, MARIA LETIZIA PETRONI, MARIO BONDI, ANGELO COMPARE, GIULIO MARCHESINI, AND THE QUOVADIS STUDY GROUP. Weight loss expectations in obese patients and treatment attrition: an observational multicenter study. Obes Res. 2005;13:1961-1969.

Objective: To investigate the influence of weight loss expectations (expected 1-year BMI loss, dream and maximum acceptable BMI) on attrition in obese patients seeking treatment.

Research Methods and Procedures: Obese subjects (1785; 1393 women; median age, 46 years; median BMI, 36.7 $\mathrm{kg} / \mathrm{m}^{2}$ ) seeking treatment in 23 medical Italian centers were evaluated. Baseline diet and weight history, weight loss expectations, and primary motivation for seeking treatment (health or improving appearance) were systematically recorded. Psychiatric distress, binge eating, and body image dissatisfaction were tested at baseline by self-administered questionnaires (Symptom Check List-90, Binge Eating Scale, and Body Uneasiness Test). Attrition and BMI change at 12 months were prospectively recorded.
\end{abstract}

Results: At 12 months, 923 of 1785 patients $(51.7 \%)$ had

Received for review January 14, 2005.

Accepted in final form August 11, 2005

The costs of publication of this article were defrayed, in part, by the payment of page charges. This article must, therefore, be hereby marked "advertisement" in accordance with 18 U.S.C. Section 1734 solely to indicate this fact.

*Villa Garda Hospital, Garda, Verona, Italy; †Department of Psychology, Catholic University, Milan, Italy; $\$$ Clinical Psychology Service and $§$ Department of Metabolic Rehabilitation, San Giuseppe Hospital, Piancavallo, Italy; IDepartment of Internal Medicine and Endocrinology, University of Modena and Reggio Emilia, Modena, Italy; and \|Unit of Metabolic Diseases, Alma Mater Studiorum, University of Bologna, Bologna, Italy.

**A complete list of participants in the QUOVADIS study has been previously published (The QUOVADIS Study: features of obese Italian patients seeking treatment at specialist centers. Diabetes Nutr Metab. 2003;16:115-24.).

Address correspondence to Giulio Marchesini, Unit of Metabolic Diseases, Alma Mater University of Bologna, Policlinico S. Orsola, Via Massarenti, 9, I-40138 Bologna, Italy.

E-mail: giulio.marchesini@unibo.it

Copyright () 2005 NAASO discontinued treatment. Compared with continuers, dropouts had a significantly lower age, a lower age at first dieting, lower dream BMI, a higher expected 1-year BMI loss, and a higher weight phobia. At logistic regression analysis, the strongest predictors of attrition at 12 months were lower age and higher expected 1-year BMI loss. The risk of drop-out increased systematically for unit increase in expected BMI loss at 12 months (hazard ratio, 1.12; 95\% confidence interval, 1.04 to $1.20 ; p=0.0018$ ). The risk was particularly elevated in the first 6 months.

Discussion: Baseline weight loss expectations are independent cognitive predictors of attrition in obese patients entering a weight-losing program; the higher the expectations, the higher attrition at 12 months. Unrealistic weight goals should be tackled at the very beginning of treatment.

Key words: attrition, dream BMI, psychiatric distress, body image, binge eating

\section{Introduction}

In 1998, the National Heart, Lung and Blood Institute recommended a $10 \%$ weight loss as the general goal of obesity management (1). The $10 \%$ recommendation derived from the observation that the obesity-associated morbidity is significantly decreased by a moderate reduction in weight, even if patients remain in the obesity range (1-4). Studies carried out in the United States (5-7) and Europe (8) found that the majority of treatment-seeking obese patients consider the recommended $10 \%$ weight loss a highly unsatisfactory goal. Their minimum acceptable weight loss expectations are over twice as large as the $10 \%$ weight loss usually attained by the best evidence-based non-surgical weight loss treatments (e.g., behavior therapy and pharmacotherapy) (9-11).

Studies on goal setting observed that when goals are not reached or the progress toward them is unsatisfactory, people have negative emotions $(12,13)$, impaired task performance (14), and often abandon their attempt to achieve the 
out-of-reach goals (15). On the basis of these observations, a few authors put forward the hypothesis that encouraging obese patients to accept more realistic weight loss goals might improve both psychological outcome and weight loss $(5,16,17)$. This task might be particularly difficult in subjects seeking treatment for appearance-related reasons, who have a lower BMI $(8,18)$, but a greater body dissatisfaction and a lower self-esteem (18).

The effect of weight loss expectations on treatment outcome has not been definitely assessed. A few studies suggested that having higher initial weight loss expectations predicts drop-out $(19,20)$, whereas one study failed to associate goal and dream BMI with attendance at sessions of behavioral therapy (21). Small retrospective studies found that having unrealistic weight goals may also contribute to poor weight maintenance (22-24). Finally, weight goals were not clearly associated with weight loss, both in the short term (25-28) and in the long term (12 to 30 months) $(21,25-28)$.

To improve our understanding on the effect of weight loss expectations on treatment outcome, we analyzed the attrition rate of treatment-seeking obese subjects participating in a large observational Italian study with 12 months of follow-up (29). At the time of study planning, treatment goals based on patients' perspectives were specifically considered and prospectively collected.

\section{Research Methods and Procedures QUOVADIS Study Planning and Protocol}

The QUOVADIS (QUality of life in Obesity: eVAluation and DIsease Surveillance) study planning and protocol were illustrated in detail in a previous paper (29). QUOVADIS is an observational study on quality of life in obese patients seeking treatments at medical centers accredited by the Italian Health Service for the treatment of obesity during 1999. Twenty-five medical centers specialized in the treatment of obesity scattered throughout Italy, from the north (Turin, Bolzano, Udine) to the south (Catania, Messina), participated in the study. The study was purely observational. All centers were expected to treat patients along the lines of their specific programs, including dieting, cognitive-behavioral therapy, drugs, and bariatric surgery $(<2 \%$ of patients). Although the theory on which the treatment was based varied dramatically among the 25 medical centers, all of the centers adopted a continuous care approach with periodic medical examination for an indefinite period of time (at least 1 year).

All obese subjects (BMI $\geq 30 \mathrm{~kg} / \mathrm{m}^{2}$ ) consecutively seeking treatment were eligible for the study, provided they were not on active treatment at the time of enrollment, were in the age range between 25 and 65 years, agreed to fill the whole package of self-administered questionnaires, and signed an informed consent to participate. A systematic evaluation of patients was planned at baseline, approximately 1 week before the beginning of treatment and at 12 months, but only 23 of 25 centers participated in the 12month follow-up. Therefore, longitudinal data are only available for a subset of patients.

The protocol was approved by the ethical committees of the individual centers, after approval by the ethical committee of the coordinating center (Azienda Ospedaliera di Bologna, Policlinico S. Orsola, Malpighi, Italy). All subjects gave written informed consent for participation.

\section{Measures}

Baseline data collection included weight and height measurement, a detailed case report form, and a package of questionnaires for psychological distress and eating behavior disorders (29).

Case Report Form. The case report form was filled by physicians at time of enrollment by directly interviewing patients. It included demographic data and a detailed diet history, with specific information on the number and the results of previous attempts to lose weight, age at first dieting, expected 1-year weight loss, and maximum acceptable and dream weight. Expected 1-year loss was defined as "the weight loss that patients were expecting to lose with treatment in the following 12 months." To help subjects indicate their expectations, this value was categorized in multiples of $10 \mathrm{~kg}$. Maximum acceptable weight was defined as "the heaviest body weight that patients could accept and tolerate," whereas dream weight was defined as "the body weight that they were dreaming to achieve, however unrealistic it was." The form also included a question on the reasons for seeking treatment. For this specific purpose, patients were asked to choose the primary motivation among three different answers: improving appearance, improving future health, and improving present health.

Psychosocial Measures. Participants completed a battery of specific questionnaires used to detect psychiatric distress, binge eating, and body image dissatisfaction.

The Symptom Check List-90 (SCL-90) ${ }^{1}$ (30) is a tool to identify psychopathological distress. For the 90 items of the test, patients score how much a problem distressed them during the previous week, with responses ranging from 0 (not at all) to 4 (extremely). The items are summarized into nine domains (somatization, obsessive-compulsive thoughts, interpersonal sensitivity, depression, anxiety, hostility, phobic anxiety, paranoid conceiving, and psychotic behavior), and a general symptom index, which is used as an indicator of overall psychological distress (31).

The Binge Eating Scale (BES) (32) includes 16 items measuring the severity of the binge eating. It examines both behavioral manifestations (eating large amounts of foods)

\footnotetext{
${ }^{1}$ Nonstandard abbreviations: SCL-90, Symptom Check List-90; BES, Binge Eating Scale; BUT, Body Uneasiness Test; HR, hazard ratio; CI, confidence interval.
} 
and feeling/cognition during a binge episode (loss of control, guilt, fear of being unable to stop eating).

The Body Uneasiness Test (BUT) (33) is a self-administered, rapid questionnaire specifically developed to evaluate concern for physical appearance, body image awareness (34 items, Part I), and body parts that most severely contribute to body dissatisfaction (37 items, Part II). The score of part I, ranging from 0 (never) to 5 (always) are combined in a Global Severity Index and in five subscales resulting from factorial analysis (weight phobia, body image concerns, avoidance, compulsive self-monitoring, depersonalization). The five subscales discriminate subjects with eating disorders from non-clinical controls (Wilk's $\lambda=0.62, p=$ 0.0001) (20). The scores of Part II are arranged into a positive symptom total and a positive symptom distress index. BUT reliability is good (Cronbach $\alpha$ value: weight phobia, 0.85; body image concern, 0.92; avoidance, 0.75 ; compulsive self-monitoring, 0.81 ; depersonalization, 0.77 ) (34).

Weight and Height. Weight was measured on a medical balance and height by a stadiometer by a medical doctor of every center involved in the study. Patients were dressed with underwear without shoes. Weight change was examined from baseline to 12 months. No data on body weight were collected at 12 months for patients who interrupted treatment.

Attrition. Attrition was evaluated at 12 months by analyzing the patients' medical records, where the date of the last medical examination and the date when patients were last seen by the centers were registered.

\section{Data Collection}

All data were stored in a large database, provided by CINECA (Casalecchio di Reno, Italy), an Interuniversity Consortium of 15 Italian Universities, through an extranet system. Participating centers accessed the system using a personal user identification and password and inserted patients' data into the database through electronic forms.

\section{Statistical Analyses}

All weight data (in kilograms) were transformed into BMI units to improve comparison between genders. A first descriptive analysis was used to obtain a qualitative evaluation of clinical data, response to questionnaires, and patients' outcomes. The principal outcomes variables were attrition (nominal) and weight loss at 12 months (continuous). ANOVA and $\chi^{2}$ test were used to test the significance of difference between continuers and drop-outs, also in relation to the main reason for seeking treatment and to gender. Correlation analysis was also performed to establish links between dream and maximum acceptable BMI and BMI change from baseline to 12 months. Logistic regression analysis was used to identify the determinants of attrition at 12 months and hierarchical regression to identify the determinants of weight change at 12 months. In a subset of 1604 cases where attrition at 12 months and time to dropout were available, the Cox regression model was used to determine the hazard ratio (HR) of drop-out as function of both expected BMI losses and other variables.

Data are reported as mean $\pm \mathrm{SD}$. Three sets of variables were simultaneously tested: anthropometric data, weight history, and psychometric data. Accordingly, the limit of significance was adjusted according to Duncan's multiple range (34) to:

$$
p^{\prime}=1-{ }^{(n-1)} \sqrt{(1-p)}
$$

where $p=0.05$ and $n=3$. The final critical value of significance was, therefore, set at 0.025 .

\section{Results}

The baseline characteristics of the whole QUOVADIS sample were described in detail in previous reports $(8,29)$. Table 1 presents the principal baseline data of the patients seeking treatment at the 23 centers that participated in the 12-month follow-up. The sample consisted of the complete records of 1785 patients (1393 women and 392 men).

Men had a significantly higher BMI at age 20, whereas women reported an earlier age at first dieting and a moderately higher maximum weight loss. In the whole population, dream BMI was $26.0 \pm 3.2 \mathrm{~kg} / \mathrm{m}^{2}$ (corresponding to a hypothetical $32 \%$ weight loss), and maximum acceptable BMI was $29.2 \pm 4.2 \mathrm{~kg} / \mathrm{m}^{2}(-23 \%)$. Present BMI and age were the strongest predictors of weight goals, whereas psychological distress, body image dissatisfaction, and eating behavior (SCL-90, BUT, and BES scores) did not significantly predict weight loss expectations. The primary motivation for weight loss was concern for future or present health. Women seeking treatment to improve appearance had a lower grade of obesity [36.9 vs. 37.9 (future health) and $38.8 \mathrm{~kg} / \mathrm{m}^{2}$ (present health); $F(2.1390)=9.56, p<$ 0.001 ], were younger [38.2 vs. 44.7 (future health) and 47.3 years (present health); $F(2.1188)=21.43, p<0.001]$, and first attempted weight loss at a younger age [23.3 vs. 26.0 (future health) and 28.7 years (present health); $F(2.1390)=$ 67.56, $p<0.001]$.

At 12 months, 923 of 1785 subjects $(51.7 \%)$ had discontinued treatment. In the 1 st week, 231 patients were lost to follow-up (13\% of total group; $25 \%$ of drop-outs). No differences were observed in the drop-out rate between men and women $\left(\chi^{2}=2.678 ; p=\right.$ not significant), but attrition was higher in subjects with a primary motivation for weight loss based on appearance (Table 2). Median time to dropout was 110 days (interquartile range, 239 days). It was not different between genders, or between subjects aged below vs. over 45 , or in subjects trying to lose weight for health concern vs. concern for body appearance. It was progressively shorter in relation to expected BMI loss [from 167 
Table 1. Baseline data of patients included in the analysis (means $\pm \mathrm{SD}$ ) or prevalence $(95 \% \mathrm{CI})$

\begin{tabular}{|c|c|c|c|}
\hline & $\begin{array}{c}\text { Women } \\
(N=1393)\end{array}$ & $\begin{array}{c}\text { Men } \\
(N=392)\end{array}$ & $p$ \\
\hline \multicolumn{4}{|l|}{ Demographic variables } \\
\hline Age (years) & $44.8 \pm 11.1$ & $44.0 \pm 10.7$ & NS \\
\hline BMI $\left(\mathrm{kg} / \mathrm{m}^{2}\right)$ & $38.2 \pm 6.3$ & $38.0 \pm 6.6$ & NS \\
\hline \multicolumn{4}{|l|}{ Historical variables } \\
\hline BMI at age $20\left(\mathrm{~kg} / \mathrm{m}^{2}\right)$ & $25.6 \pm 5.2$ & $27.0 \pm 5.1$ & $<0.001$ \\
\hline Maximum BMI $\left(\mathrm{kg} / \mathrm{m}^{2}\right)$ & $39.3 \pm 6.8$ & $39.2 \pm 7.2$ & NS \\
\hline Age at first dieting (years) & $26.8 \pm 11.2$ & $28.9 \pm 10.9$ & 0.006 \\
\hline Maximum weight loss (\%) & $16.5 \pm 9.0$ & $15.1 \pm 9.9$ & 0.021 \\
\hline \multicolumn{4}{|l|}{ Weight loss expectations } \\
\hline Maximum acceptable BMI $\left(\mathrm{kg} / \mathrm{m}^{2}\right)$ & $28.9 \pm 4.2$ & $30.2 \pm 4.0$ & $<0.001$ \\
\hline Dream BMI $\left(\mathrm{kg} / \mathrm{m}^{2}\right)$ & $25.6 \pm 3.2$ & $27.3 \pm 2.7$ & $<0.001$ \\
\hline Expected 1-year BMI Loss $\left(\mathrm{kg} / \mathrm{m}^{2}\right)$ & $10.6 \pm 3.9$ & $8.7 \pm 3.4$ & $<0.001$ \\
\hline Primary reason for seeking treatment & & & $<0.001$ \\
\hline Concern for present health $(\%)$ & $49.8(47.2$ to 52.6$)$ & $55.1(50.0$ to 59.8$)$ & \\
\hline Concern for future health (\%) & 32.1 (29.7 to 34.6$)$ & $37.5(32.7$ to 42.3$)$ & \\
\hline Concern for appearance $(\%)$ & 18.1 (16.1 to 20.2$)$ & $7.4(5.1$ to 10.3$)$ & \\
\hline
\end{tabular}

NS, not significant.

(interquartile range, 261) days in subjects with expected BMI loss $<5 \mathrm{~kg} / \mathrm{m}^{2}$, to 134 (233), 90 (219), and 53 (218) days for expected BMI loss in the range 5 to 9,9 to 13 , and above $13 \mathrm{~kg} / \mathrm{m}^{2}$, respectively; $p=0.024$, Kruskall-Wallis test].

In comparison with subjects in active follow-up (continuers), subjects who voluntary discontinued treatment (dropouts) were significantly younger $[F(1.1783)=28.645 ; p<$ $0.001]$ and had a significantly lower age at first dieting $[F(1.1471)=7.270 ; p=0.007]$, lower dream BMI $[F(1.1783)=11.629 ; p<0.001]$, and a higher expected 1 -year BMI loss $[F(1.1781)=13.645 ; p<0.001]$ (Table $2)$. In addition, drop-outs also had moderately higher weight phobia scores at the BUT questionnaire $(p=0.033)$ (Table 3).

Logistic regression analyses revealed that the strongest predictors of attrition at 12 months were age $(\beta=-0.019$; $\left.\chi^{2}=7.594 ; p=0.006\right)$ and expected 1-year BMI loss $(\beta=$ $\left.0.043 ; \chi^{2}=6.077 ; p=0.014\right)$. The risk of drop-out increased by $12 \%$ for unit increase in expected BMI loss at 12 months [hazard ratio (HR), 1.12; 95\% confidence interval (CI), 1.04 to $1.20 ; p=0.0018]$. The risk was larger in the first 6 months (HR, 1.19; 1.09 to $1.30 ; p=0.0001)$. In comparison with subjects with an expected BMI loss $<5$ $\mathrm{kg} / \mathrm{m}^{2}$, the HR of drop-out was 1.20 (0.95 to $1.53 ; p=$ 0.133 ) for expected BMI losses between 5 and $9 \mathrm{~kg} / \mathrm{m}^{2}, 1.34$
(1.06 to $1.71 ; p=0.016$ ) for expected losses in the range 9 to 13 , and 1.44 ( 1.12 to $1.85 ; p=0.004$ ) for expected losses above $13 \mathrm{~kg} / \mathrm{m}^{2}$ (Figure 1).

In a Cox model, concern for appearance markedly increased the risk of drop-out in comparison with health concern, both at 6 months (HR, 1.42; 95\% CI, 1.15 to 1.75 ; $p=0.0012)$ and at 1 year $(1.42,1.20$ to $1.68 ; p<0.0001)$.

At 12 months, continuers had reduced their BMI from $38.4 \pm 6.4$ to $35.2 \pm 6.4 \mathrm{~kg} / \mathrm{m}^{2}[t(859)=26.22 ; p<$ 0.001]. The BMI change was significantly and negatively related to the following continuous variables adjusted for basal BMI: dream BMI $(r=-0.08 ; p<0.05)$, age $(r=$ $-0.12 ; p<0.01)$, maximum BMI $(r=-0.09 ; p<0.01)$, BMI at age 20 years $(r=0.07 ; p<0.05)$, BES total scale $(r=-0.12, p=0.001)$, and SCL-90 Global Severity Index $(r=-0.10, p=0.004)$ and several individual subscales (somatization, $r=-0.11, p=0.001$; obsessive-compulsive thoughts, $r=-0.11, p=0.001$; depression, $r=-0.11$, $p=0.001$; anxiety, $r=-0.11, p=0.001)$. Hierarchical regression analyses revealed that the strongest predictor of BMI loss in continuers was baseline BMI ( $\beta=0.28, t=$ 7.70, $p<0.001)$. The predictors that were entered in the following steps were age $(\beta=-0.16, t=-3.54, p<$ $0.001)$, BES score $(\beta=-0.08, t=-2.08, p<0.05)$, age at first dieting $(\beta=-0.10, t=-2.09, p<0.05)$, and the score of the obsessive-compulsive subscale of SCL-90 ( $\beta=$ $-0.08, t=-2.06, p<0.05)$. 
Table 2. Baseline data in obese subjects, according to drop-out at 12 months (mean $\pm \mathrm{SD})$ or prevalence $(95 \%$ CI)

\begin{tabular}{|c|c|c|c|}
\hline & $\begin{array}{l}\text { Continuers } \\
(N=862)\end{array}$ & $\begin{array}{l}\text { Drop-outs } \\
(N=923)\end{array}$ & $p$ \\
\hline \multicolumn{4}{|l|}{ Demographic variables } \\
\hline Age (years) & $46.1 \pm 10.9$ & $43.3 \pm 11.0$ & $<0.001$ \\
\hline BMI $\left(\mathrm{kg} / \mathrm{m}^{2}\right)$ & $38.4 \pm 6.4$ & $38.2 \pm 6.4$ & NS \\
\hline \multicolumn{4}{|l|}{ Historical variables } \\
\hline BMI at age $20\left(\mathrm{~kg} / \mathrm{m}^{2}\right)$ & $25.7 \pm 4.8$ & $26.1 \pm 5.5$ & NS \\
\hline Maximum BMI $\left(\mathrm{kg} / \mathrm{m}^{2}\right)$ & $39.3 \pm 6.8$ & $39.2 \pm 6.9$ & NS \\
\hline Age at first dieting (years) & $28.0 \pm 11.1$ & $26.5 \pm 11.2$ & 0.007 \\
\hline Maximum weight loss (\%) & $15.9 \pm 8.8$ & $16.6 \pm 9.5$ & NS \\
\hline \multicolumn{4}{|l|}{ Weight loss expectations } \\
\hline Maximum acceptable BMI $\left(\mathrm{kg} / \mathrm{m}^{2}\right)$ & $29.4 \pm 4.1$ & $29.1 \pm 4.3$ & NS \\
\hline Dream BMI $\left(\mathrm{kg} / \mathrm{m}^{2}\right)$ & $26.2 \pm 3.1$ & $25.7 \pm 3.3$ & 0.001 \\
\hline Expected 1-year BMI loss $\left(\mathrm{kg} / \mathrm{m}^{2}\right)$ & $9.8 \pm 3.7$ & $10.5 \pm 3.9$ & $<0.001$ \\
\hline \multicolumn{4}{|l|}{ Primary reason for seeking treatment } \\
\hline Concern for present health $(\%)$ & 52.4 (49.0 to 55.7$)$ & $49.6(46.2$ to 52.8$)$ & 0.0002 \\
\hline Concern for future health $(\%)$ & $35.8(32.6$ to 39.0$)$ & $30.9(28.0$ to 33.9$)$ & \\
\hline Concern for appearance $(\%)$ & $11.7(9.7$ to 14.0$)$ & $19.5(17.0$ to 22.1$)$ & \\
\hline
\end{tabular}

NS, not significant.

\section{Discussion}

This study confirms that higher weight loss expectations are positively associated with attrition at 12 months in treatment-seeking obese persons. The study has several strengths. First, it evaluated the effect of weight loss expectation in the real world treatment of 23 obesity medical centers scattered throughout Italy with heterogeneous modalities of care. Second, it evaluated a set of weight goal determinants, namely, expected 1-year weight loss as well as maximum acceptable and dream BMI, prospectively collected in the largest sample of obese men and women so far examined. Third, it included a relatively long follow-up time to evaluate attrition in a continuous care model of treatment. Fourth, it evaluated the effect of a large number of baseline characteristics of patients on attrition.

Drop-out is a crucial issue in the failure of obesity treatment; attrition rates in obesity trials range from $10 \%$ to $80 \%$ (35). Also, in strictly controlled single-center randomized studies, the attrition rate exceeds $40 \%$ at 12 months, independently of the type of dietary program (36). Attrition may be lower in subjects treated by cognitive-behavioral therapy (37), but rates are expected to be even higher outside controlled studies (38). Unfortunately, only a few studies have examined the reasons of attrition. In a 1992 review, Wadden and Letizia (39) pointed out that binge eating, significant life stress (including financial problems), and small weight loss early in the treatment were the most important predictors of attrition. Andersson and Rössner (40) were the first to show that drop-out might stem from decreased motivation, and their results were confirmed by Lantz et al. (41), who reported lack of motivation as a leading causes of premature withdrawal. Reasons are probably different in different clinical set-ups. In obese outpatients, lack of depression was an attrition factor (42), and in a similar healthy series, Teixeira et al. (20) first showed that initial weight loss expectations distinguished continuers from drop-outs in a 16-week lifestyle weight loss program.

Our study found a global drop-out rate of $51.7 \%$, thus confirming that drop-out is one of the major problems in the treatment of obesity in naturalistic settings. Weight loss expectations seem to play a major role in treatment outcome, being significantly associated with drop-out rate. Patients with lower dream BMI and higher expected 1-year BMI loss had the highest drop-out rate, which increased by $10 \%$ for any point of increase of expected BMI loss. Our study adds two original observations to the area of unrealistic expectations on obesity treatment outcome: the time to drop-out is progressively shorter in relation to expected BMI loss, and attrition is influenced also by goals other than weight loss.

Other factors associated with drop-out were, indeed, a younger age, a lower age at first dieting, and a higher weight 
Table 3. Psychometric testing in obese subjects, according to drop-out; data are presented as prevalence and $95 \%$ CI of scores exceeding the upper limit of norm (BES and SCL-90) or as median and range (BUT)

\begin{tabular}{|c|c|c|c|}
\hline & $\begin{array}{l}\text { Continuers } \\
(N=862)\end{array}$ & $\begin{array}{l}\text { Drop-outs } \\
(N=923)\end{array}$ & $p$ \\
\hline \multicolumn{4}{|l|}{ BES ( $\%$ and $95 \% \mathrm{CI}$ ) } \\
\hline Score & $36.9(33.7$ to 40.1$)$ & $40.0(36.8$ to 43.1$)$ & NS \\
\hline \multicolumn{4}{|l|}{ SCL-90 (\% and 95\% CI) } \\
\hline Somatization & $47.8(44.4$ to 51.1$)$ & 48.1 (44.8 to 51.3$)$ & NS \\
\hline Obsessive-compulsive thoughts & 36.8 (33.6 to 40.0$)$ & $34.2(31.2$ to 37.3$)$ & NS \\
\hline Interpersonal sensitivity & $34.2(31.1$ to 37.4$)$ & $33.3(30.2$ to 36.3$)$ & NS \\
\hline Depression & 37.7 (34.5 to 40.9$)$ & $37.4(34.3$ to 40.5$)$ & NS \\
\hline Anxiety & $31.7(28,6$ to 34.8$)$ & $30.8(27.8$ to 33.8$)$ & NS \\
\hline Hostility & 26.5 (23.6 to 29.4$)$ & 27.1 (24.3 to 30.0$)$ & NS \\
\hline Phobic anxiety & $13.1(11.0$ to 15.5$)$ & $11.5(9.5$ to 13.6$)$ & NS \\
\hline Paranoid conceiving & $34.2(31.1$ to 37.4$)$ & $34.2(31.2$ to 37.3$)$ & NS \\
\hline Psychotic behavior & 15.1 (12.8 to 17.6$)$ & $14.2(12.0$ to 16.5$)$ & NS \\
\hline Global Severity Index & $29.0(26.0$ to 32.1$)$ & $28.6(25.7$ to 31.5$)$ & NS \\
\hline \multicolumn{4}{|l|}{ BUT (median and range) } \\
\hline Weight phobia & $1.86(0$ to 5$)$ & $1.87(0$ to 5$)$ & 0.033 \\
\hline Body image concern & $2.11(0$ to 5$)$ & $2.22(0$ to 5$)$ & NS \\
\hline Avoidance & $0.83(0$ to 5$)$ & $0.83(0$ to 5$)$ & NS \\
\hline Compulsive self-monitoring & $0.67(0$ to 5$)$ & $0.83(0$ to 5$)$ & NS \\
\hline Depersonalization & $0.60(0$ to 5$)$ & $0.60(0$ to 5$)$ & NS \\
\hline Global Severity Index & $1.38(0$ to 4.9$)$ & $1.41(0$ to 4.7$)$ & NS \\
\hline Positive symptom distress index & $2.64(0$ to 5$)$ & $2.77(0$ to 5$)$ & NS \\
\hline
\end{tabular}

NS, not significant.

phobia, whose influence on drop-out seems reasonable, as well as concern for appearance as the main reason for seeking treatment. However, a higher expected 1-year BMI loss was confirmed by logistic regression as one of the factors more closely associated with attrition at 12 months, without differences between men and women.

According to our data, the negative role of unrealistic weight loss expectations on treatment outcome is not confined to failure of weight maintenance (22-24) but particularly increases the attrition rate during the early phase of weight loss. One in eight Italian patients seeking treatment for obesity does not attend follow-up visits after the first contact with the obesity center, and this drop-out rate accounts for one in four patients losing contact in a 1-year follow-up. Our protocol does not provide any information to explain this very early drop-out, and direct interviews with patients might be needed to collect data. However, a post hoc analysis after removal of drop-outs occurring after the first contact did not change the results (not reported in detail). Baseline weight loss expectations maintain the independent role as cognitive predictors of attrition observed in the general analysis of the general QUOVADIS population, contrary to what was reported by Texeira et al. (20) in a different setting. This conclusion applies to the general, open Italian population, but different therapeutic proposals might variably affect drop-out rate and time to drop-out. In our series, a cognitive-behavioral weight losing approach was programmed in $<50 \%$ of cases (29) in the different centers, being possibly the reason for the high drop-out rate.

In continuers, weight loss expectations were less important in predicting BMI change at 12 months than other baseline variables, such as BMI, age, BES score, age at first dieting, and the scores of SCL-90 subscales. This means that the desire to lose more weight is not associated with greater weight loss at 12 months. The observation that higher dream BMI was negatively associated with BMI change at 1 year indicates that the desire to lose more weight could have a negative effect also on weight loss. This paradoxical result might, however, stem from the higher drop-out rate of subjects with unrealistic weight loss expectations. Data on weight loss in drop-outs were not available in our study, and this issue remains speculative. 


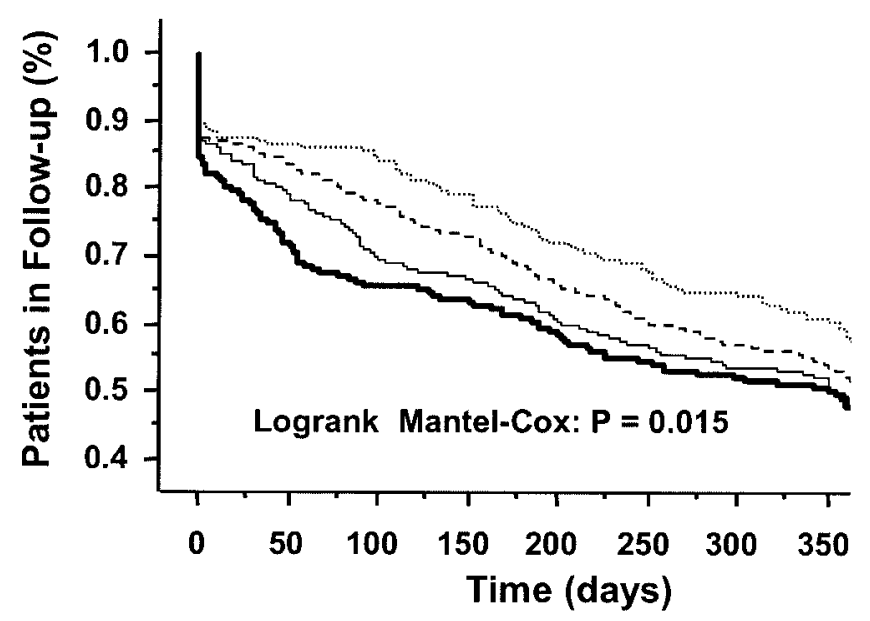

Figure 1: Percentage of patients in active treatment according to expected BMI loss. The dotted line represents subjects reporting an expected BMI loss below $5 \mathrm{~kg} / \mathrm{m}^{2}$, the dashed line represents subjects with an expected loss between 5 and $9 \mathrm{~kg} / \mathrm{m}^{2}$, the thin continuous line represents an expected loss between 9 and 13 $\mathrm{kg} / \mathrm{m}^{2}$, and the bold line represents subjects with larger expected BMI loss (over $13 \mathrm{~kg} / \mathrm{m}^{2}$ ) (for relative risk compared with expected BMI loss $<5 \mathrm{~kg} / \mathrm{m}^{2}$, see text). The differences are entirely due to attrition in the first 3 months.

Indeed, a potential factor linking unrealistic weight loss expectations and attrition could be the dissatisfaction with weight loss obtained with treatment. A partial support to this hypothesis comes from the observation that the difference between weight goals and weight achieved with treatment is correlated with posttreatment satisfaction (5). As the difference increases, so does dissatisfaction, and frustrated patients tend to abandon treatment. In a recent study, dissatisfaction with the results was reported as a major cause of attrition by $25 \%$ of drop-outs (43). Some data are also available on the association between weight loss satisfaction and weight maintenance. A qualitative retrospective study (in-depth individual interview and group interview) found that obese regainers, but not the maintainers, had failed to achieve their initial weight goals and were highly dissatisfied with body weight achieved by treatment (44). A longitudinal study on the effect of behavior therapy found that satisfaction with body weight achieved during treatment was significantly associated with better weight maintenance (45). Future research should clarify the complex link among baseline weight loss expectations, weight loss, weight loss satisfaction, and attrition. A particular attention should be given to factors that might improve satisfaction with weight loss independently of weight goals at the start of the treatment.

These data have clinical implications. The strong association between unrealistic weight loss expectations and dropout indicates that the problem of weight loss goals should be addressed both in the initial interview and during the entire course of the treatment. This would help to detect and to address promptly any warning sign of weight loss dissatisfaction, thus minimizing the risk of attrition. In this respect, young obese subjects with early age of first dieting, high weight loss expectations, and subjects seeking treatment for appearance concern represent a high-risk group. This population needs assistance to reduce unrealistic goals, a task that may be particularly difficult in subjects with body image dissatisfaction, seeking treatment for appearance concern. Specific strategies to change weight goals have been recently described in the modern cognitive-behavioral treatments of obesity (46). A recent randomized pilot study found that a cognitive-behavioral intervention designed to modify unrealistic expectations produces more realistic weight loss expectations than a standard behavior treatment, but it does not produce any significantly better maintenance of lost weight (47). Finally, although not tested in the present research, our clinical experience with obese patients suggests that a trusting and collaborative relationship between physician and patient is a crucial aspect favoring the modification of unrealistic weight goals.

The study has some limitations. Firstly, the focus on weight goals comes from the analysis of a very large population, but in individual patients and in different settings, the reason(s) for attrition might be extremely variable. Our observations are limited to obese subjects seeking treatment in a medical setting and, therefore, do not provide information on the large number of obese subjects who do not seek treatment or who seek help in non-medical settings. It is largely possible that obese subjects referring to a nonmedical center might have different weight goals and other primary motivation to weight loss and, therefore, different reasons of drop-out. Secondly, BMI at time of attrition was not systematically recorded. This limitation does not permit an exact assessment whether unrealistic weight goals influence the drop-out process during the weight loss stage (as is probably the case on the basis of time to drop-out) or later, during the maintenance period after weight loss. In the first case, strategies are needed to change the unrealistic weight goals since the very beginning of treatment. Thirdly, the data of the present study do not provide information about longitudinal changes in weight goal expectations and how these changes could influence both attrition and weight change. Finally, the study did not use the goals and relative weight questionnaire (5) (not yet available in the Italian version at the time of the study), which is presently considered the standard instrument for evaluating weight loss expectations. Our definitions of maximum acceptable weight and dream weight were slightly different from those used in the American studies (5-7). This limits the use of our data for cross-cultural comparison with other non-Italian obese samples.

Future studies should evaluate whether changes from unrealistic to more realistic weight loss goals may be ob- 
tained by a simple educational approach based on the clinical benefits of a modest weight loss or it is necessary to adopt more complex cognitive-behavioral strategies. Such interventions should be devised to change the unrealistic attitudes on weight loss goals and to improve body weight and shape dissatisfaction. The final goal is to reduce the attrition rate, which remains the crucial issue in the management of obesity.

\section{Acknowledgment}

The QUOVADIS study was supported by an unrestricted grant from BRACCO Imaging S.p.A., Milan, Italy.

\section{References}

1. Clinical Guidelines on the Identification, Evaluation, and Treatment of Overweight and Obesity in Adults-The Evidence Report. National Institutes of Health. Obes Res. 1998;6 Suppl 2:51S-209S.

2. Kanders BS, Blackburn G. Reducing primary risk factors by therapeutic weight loss. In: Wadden TA, VanItallie TB, eds. Treatment of Seriously Obese Patients. New York, NY: Guilford Press; 1992, pp. 213-30.

3. Goldstein DJ. Beneficial health effects of modest weight loss. Int J Obes Relat Metab Disord. 1992;16:397-415.

4. Blackburn G. Effect of degree of weight loss on health benefits. Obes Res. 1995;3(Suppl 2):211s-6s.

5. Foster GD, Wadden TA, Vogt RA, Brewer G. What is a reasonable weight loss? Patients' expectations and evaluations of obesity treatment outcomes. J Consult Clin Psychol. 1997; 65:79-85.

6. Foster GD, Wadden TA, Phelan S, Sarwer DB, Sanderson RS. Obese patients' perceptions of treatment outcomes and the factors that influence them. Arch Intern Med. 2001;161: 2133-9.

7. Masheb RM, Grilo CM. Weight loss expectations in patients with binge-eating disorder. Obes Res. 2002;10:309-14.

8. Dalle Grave R, Calugi S, Magri F, et al. Weight loss expectations in obese patients seeking treatment at medical centers. Obes Res. 2004;12:2005-12.

9. Bray GA. Pharmacological treatment of obesity. In: Bray GA, Bouchard C, James WPT, eds. Handbook of Obesity. New York, NY: Marcel Decker; 1998, pp. 953-76.

10. Wadden TA, Foster GD. Behavioral treatment of obesity. Med Clin North Am. 2000;84:441-61.

11. Yanovski SZ, Yanovski JA. Obesity. N Engl J Med. 2002; 346:591-602.

12. Wicklund RA, Gollwitzer PM. Symbolic Self-Completion. Hillsdale, NJ: Lawrence Erlbaum Associates; 1982.

13. Carver CS, Sheier MF. Origins and functions of positive and negative affect: a control-process view. Psychol Rev. 1990;97: 19-35.

14. Cervone D, Jiwani N, Wood R. Goal setting and the differential influence of self-regulatory processes on complex decision-making performance. J Pers Soc Psychol. 1991;61:25766.

15. Klinger E. Consequences of commitment to and disengagement from incentives. Psychol Rev. 1975;82:223-31.
16. Foster GD, Kendall PC. The realistic treatment of obesity: changing the scale of success. Clin Psychol Rev. 1994;14:70136.

17. Cooper Z, Fairburn CG, Hawker DM. Cognitive-Behavioral Treatment of Obesity. New York, NY: The Guilford Press; 2003.

18. Reas DL, Masheb RM, Grilo CM. Appearance vs. health reasons for seeking treatment among obese patients with binge eating disorder. Obes Res. 2004;12:758-60.

19. Teixeira PJ, Going SB, Houtkooper LB, et al. Weight loss readiness in middle-aged women: psychosocial predictors of success for behavioral weight reduction. J Behav Med. 2002; 25:499-523.

20. Teixeira PJ, Going SB, Houtkooper LB, et al. Pretreatment predictors of attrition and successful weight management in women. Int J Obes Relat Metab Disord. 2004;28:1124-33.

21. Linde JA, Jeffery RW, Finch EA, Ng DM, Rothman AJ. Are unrealistic weight loss goals associated with outcomes for overweight women? Obes Res. 2004;12:569-76.

22. Colvin RH, Olson SB. A descriptive analysis of men and women who have lost significant weight and are highly successful at maintaining the loss. Addict Behav. 1983;8: 287-95.

23. Marston AR, Criss J. Maintenance of successful weight loss: incidence and prediction. Int J Obes. 1984;8:435-9.

24. Klem ML, Wing RR, McGuire MT, Seagle HM, Hill JO. A descriptive study of individuals successful at long-term maintenance of substantial weight loss. Am J Clin Nutr. 1997;66: 239-46.

25. Kincey J. Target setting, self-reinforcement pattern and locus of control orientation as predictors of outcome in a behavioural weight-loss programme. Behav Res Ther. 1980;18:13945.

26. Bradley I, Poser EG, Johnson JA. Outcome expectation ratings as predictors of success in weight reduction. $J$ Clin Psychol. 1980;36:500-2.

27. Bonato DP, Boland FJ. Predictors of weight loss at the end of treatment and 1-year follow-up for a behavioral weight loss program. Int J Eat Disord. 1987;6:573-7.

28. Jeffery RW, Wing RR, Mayer RR. Are smaller weight losses or more achievable weight loss goals better in the long term for obese patients? J Consult Clin Psychol. 1998;66: 641-5.

29. Melchionda N, Marchesini G, Apolone G, et al. The QUOVADIS study: features of obese Italian patients seeking treatment at specialist centers. Diabetes Nutr Metab. 2003;16:115-24.

30. Derogatis LR, Rickels K, Rock AF. The S.C.L. 90 and the M.M.P.I.: a step in the validation of a new self-report scale. Br J Psychiatry. 1976;128:280-9.

31. Derogatis LR, Cleary PA. Confirmation of the dimensional structure of the SCL-90: a study in construct validity. J Clin Psychol. 1977;33:981-9.

32. Gormally J, Block S, Daston S, Rardin D. The assessment of binge eating severity among obese persons. Addict Behav. 1982;7:47-55.

33. Cuzzolaro M, Vetrone G, Marano G, Battacchi M. Body Uneasyness Test. In: Conti L, ed. Repertorio delle Scale di 
Valutazione in Psichiatria. 3rd vol. Firenze, Italy: Società Editrice Universo; 2000, pp. 1759-61.

34. Duncan DB. Multiple range test for correlated and heteroscedastic means. Biometrics. 1957;13:164-204.

35. Richman R, Burns CM, Steinbeck K, Caterson L. Factors influencing completion and attrition in a weight control programme. In: Ailhaud G, Guy-Grand B, Lafontane M, Ricquier D, eds. Obesity in Europe 91. London, United Kingdom; John Libbey; 1992, pp. 167-71.

36. Dansinger ML, Gleason JA, Griffith JL, Selker HP, Schaefer EJ. Comparison of the Atkins, Ornish, Weight Watchers, and Zone diets for weight loss and heart disease risk reduction: a randomized trial. JAMA. 2005;293:43-53.

37. Wing RR. Behavioral approaches to the treatment of obesity. In: Bray GA, Bouchard C, James PT, eds. Handbook of Obesity: Etiology and Pathophysiology. New York, NY: Marcel Dekker; 1998, pp. 855-73.

38. Melchionda N, Besteghi L, Di Domizio S, et al. Cognitive behavioural therapy for obesity: one-year follow-up in a clinical setting. Eat Weight Disord. 2003;8:188-93.

39. Wadden TA, Letizia KA. Predictors of attrition in weight loss in patients treated by moderate and severe caloric restriction. In: Wadden TA, VanItallie TB, eds. Treatment of the Seriously Obese Patients. New York, NY: The Guilford Press; 1992, pp. 383-410.
40. Andersson I, Rossner S. Weight development, drop-out pattern and changes in obesity-related risk factors after two years treatment of obese men. Int J Obes Relat Metab Disord. 1997;21:211-6.

41. Lantz H, Peltonen M, Agren L, Torgerson JS. A dietary and behavioural programme for the treatment of obesity: a 4-year clinical trial and a long-term posttreatment follow-up. J Intern Med. 2003;254:272-9.

42. Inelmen EM, Toffanello ED, Enzi G, et al. Predictors of drop-out in overweight and obese outpatients. Int J Obes Relat Metab Disord. 2005;29:122-8.

43. Dalle Grave R, Melchionda N, Calugi S, et al. Continuous care in the treatment of obesity: an observational multicentre study. J Intern Med. 2005;258:265-73.

44. Byrne S, Cooper Z, Fairburn C. Weight maintenance and relapse in obesity: a qualitative study. Int J Obes Relat Metab Disord. 2003;27:955-62.

45. Foster GD, Phelan S, Wadden TA, Gill D, Ermold J, Didie E. Promoting more modest weight losses: a pilot study. Obes Res. 2004;12:1271-7.

46. Cooper Z, Fairburn CG. A new cognitive behavioural approach to the treatment of obesity. Behav Res Ther. 2001;39: 499-511.

47. Ames GE, Perri MG, Fox LD, et al. Changing weight-loss expectations: a randomized pilot study. Eat Behav. 2005;6: 259-69. 